\title{
Overview of Sport History in Iran: Prehistory, Ancient and Modernization
}

\author{
Hamid Ghasemi*1 ${ }^{1}$ Nazanin Rasekh ${ }^{2}$, Leila Izadparast ${ }^{3}$
}

1. Associate Professor, Sport Management Group, Payam-e-Noor University of Tehran, Iran.

H ghasemi@pnu.ac.ir

2. Assistant Professor of Sport Management, Sport Science Research Institute, Tehran, Iran. n.rasekh6663@gmail.com

3. $\mathrm{PhD}$ of Sport Management, Payam-e-Noor University of Tehran, Iran.

leilaizadparast@yahoo.com

\begin{abstract}
The article reviews Iranian sports in three periods: prehistoric, ancient and modern. In prehistoric times, remaining cases have shown the existence of movement activities based on recreational and religious ceremonies. In the period of ancient history, documents such as Hasanlu Golden Cup and Arjan Cup, and in the continuation of architectures leftover from different eras, refer to the prosperity of sports activities with different approaches. Among all kinds of activities, Iranian zoorkhaneh sport has a significant cultural background and effect. Modern sports entered Iran through embassies, oil contractors, Western-educated students, and military representatives in other countries (in modern era). Iran became a member of the International Olympic Committee in 1947 and won its first Olympic medal in 1948. Entering the 21st century, the sport industry in Iran began to grow and the number of clubs, sports careers and sports science students in universities increased significantly. The growing dimension of attention and interest in sports among Iranians shows that sports will be one of the main areas in Iran's development in the future.
\end{abstract}

KEYWORDS: Sport History; Iran; Zoorkhaneh Sport; Arjan Cup, Traditional Sport

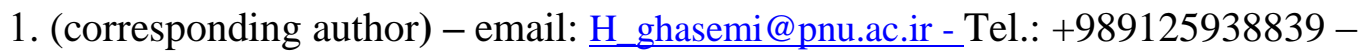
ORCID: https://orcid.org/0000-0001-5305-3331 


\section{Introduction}

Numerous behavioural patterns such as play, game, sport, exercise, physical activity, physical education and physical fitness have been studied in sport history. Although all of these concepts are considered to as sport concept, there are differences between these concepts. Play is an activity that is unstructured and dependent on physical instincts such as gliding and diving. The game is a contract activity and includes local and amateur games such as street football, competitive with local or international laws. Sports is competitive games that winning and losing are important to them and they also have universal standard rules such as football, volleyball and wrestling. Exercise refers to regular activities aimed at increasing ability and skill in certain areas such as football or health. Physical activity is defined as any bodily movement produced by skeletal muscles that requires energy expenditure such as walking, gardening, and climbing stairs. Physical education is an educational approach to movement with an emphasis on the growth of the individual from different dimensions with physical activities in the educational system. Physical fitness is activities for health or special skills. Any different types of sport activity usually have one or more objectives such as health, defensive, competitive, recreational, monetization, ritual, and educational. The development of these sports objectives and its specialization give rise to institutions and structures including school sports, university sports, recreational sports, championship sports, professional sports, employee sports, workers sports, military sports, sports for the disabled, and ritual sport. There are various categories of historical periods, which one of the best is to review the history of Iranian sports based on 'prehistory, ancient history, and the modern era (Ghasemi, H., Keshkar, S., Rasekh, N. and Izadparast, L., 2020).

In each period of time, some aspects as social history perspective, the first sports practices, and representations of effect of sports in different dimension of life as culture perspective are important. It is important knowing the way individuals are slowly building entire institutions around sports (creating rules, administrations, and competitions). This subject help to understand possibilities where documents are about sport in history. The explanatory potentials of sport are very strong and regarding this amazing potential, we can dedicate to pursue every possible effort, to identify new archives, to take this history to a higher epistemological level (Grégory, 2017).

\section{Methods}

The research method was qualitative and historical and the data were collected by library method. The pattern of data organization was research based on data categorization in three time periods 'prehistory, ancient history and modern history'. Data analysis was performed based on the time trend of changes in the three reference periods.

\section{Results}

The research findings are organized into three sections: prehistoric, ancient and modern history. 


\section{Sport in Prehistory of Iran}

Before the advent of civilizations and the phenomenon of urbanization, sports activities were considered with defensive, physical, religious, and in some cases recreational approaches. In fact, 'urbanization and trade' provided the conditions for the emergence of 'civilizations'. From this period onwards, 'more purposeful physical activities with preparatory or recreational approaches' are seen in history. There is a lot of 'painting and ceramic' showing group activities in the form of 'dance and rhythmic movements'. For example, Figure 1 shows images of group movements such as dancing on piece of ceramics from six to eight thousand years ago (Salahshoor, 2018).

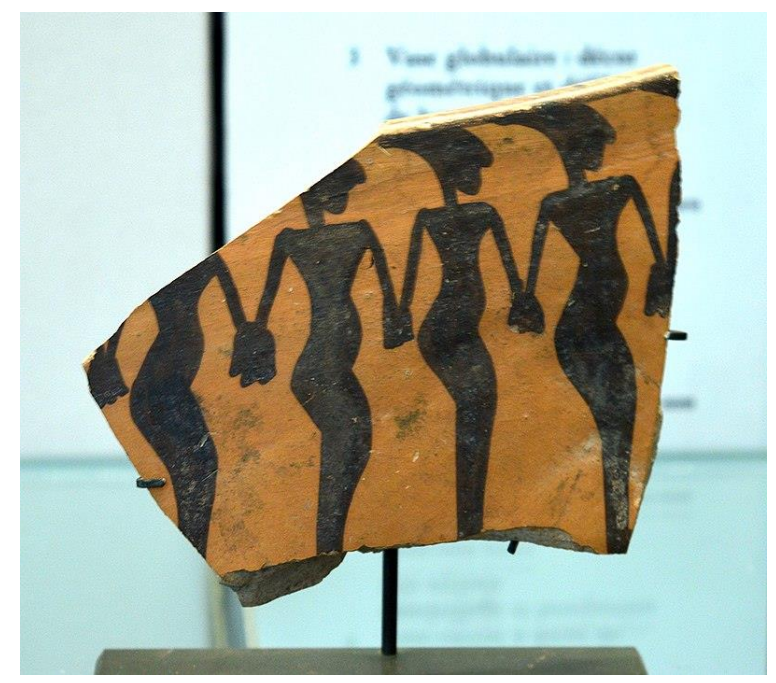

Figure 1. Dancers on a Piece of Ceramic from Cheshmeh-Ali (Shahr-e-Rey), Iran, 5000 BC now at the Louvre

\section{Sport in Ancient History of Iran}

The civilizations formed in the region of Iran are among the oldest civilizations in the world. Numerous documents have been identified from the existence of various ritual and ceremonial sports movements in different regions of Iran.

One of the oldest of these documents is the Hasanlu Golden Cup (more than 1000 years BC) with images of 'chariot riding, archery, boxing and fitness' (Ghasemi, and Keshkar, 2011). You can see Hasanlu Golden Cup in Figure 2.
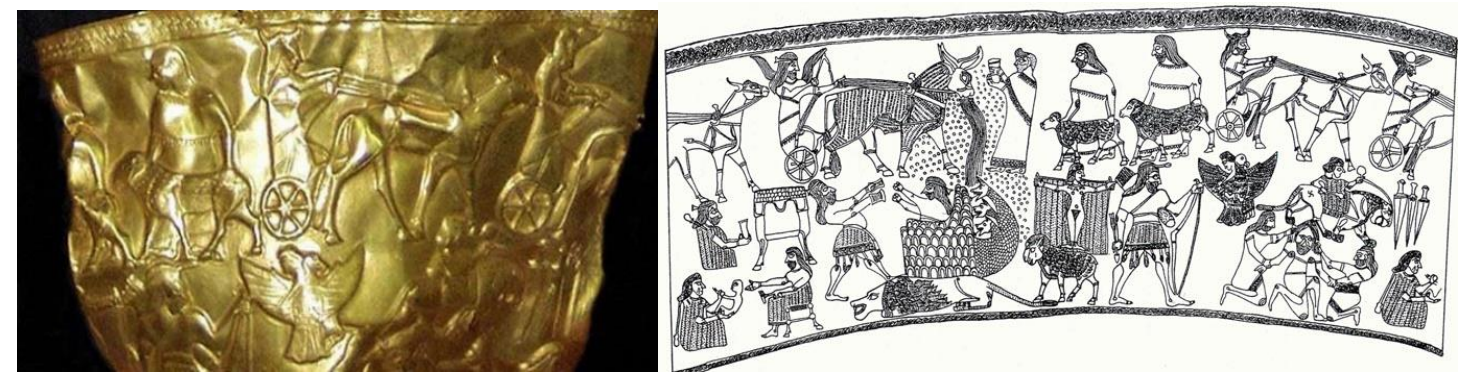

Figure 2. The Hasanlu Golden Cup, about 1000 BC, now at National Museum of Iran 
Other documents is the Arjan Cup (Figure 3). Arjan cup is related to $800 \mathrm{BC}$ and has five rings. This cup represents various sports of acrobat and gymnastic. In this work of art, you can see a variety of sports movements such as 'gymnastics, wrestling, martial arts, carrying a torch' along with 'holding music and other symbols of a sports festival'. This cup was chosen as the symbol of the Iran's convoy to participate in the Tokyo Olympic Games in 2020, which was postponed to 2021 due to the Corona pandemic (Ghasemi, et al., 2020).

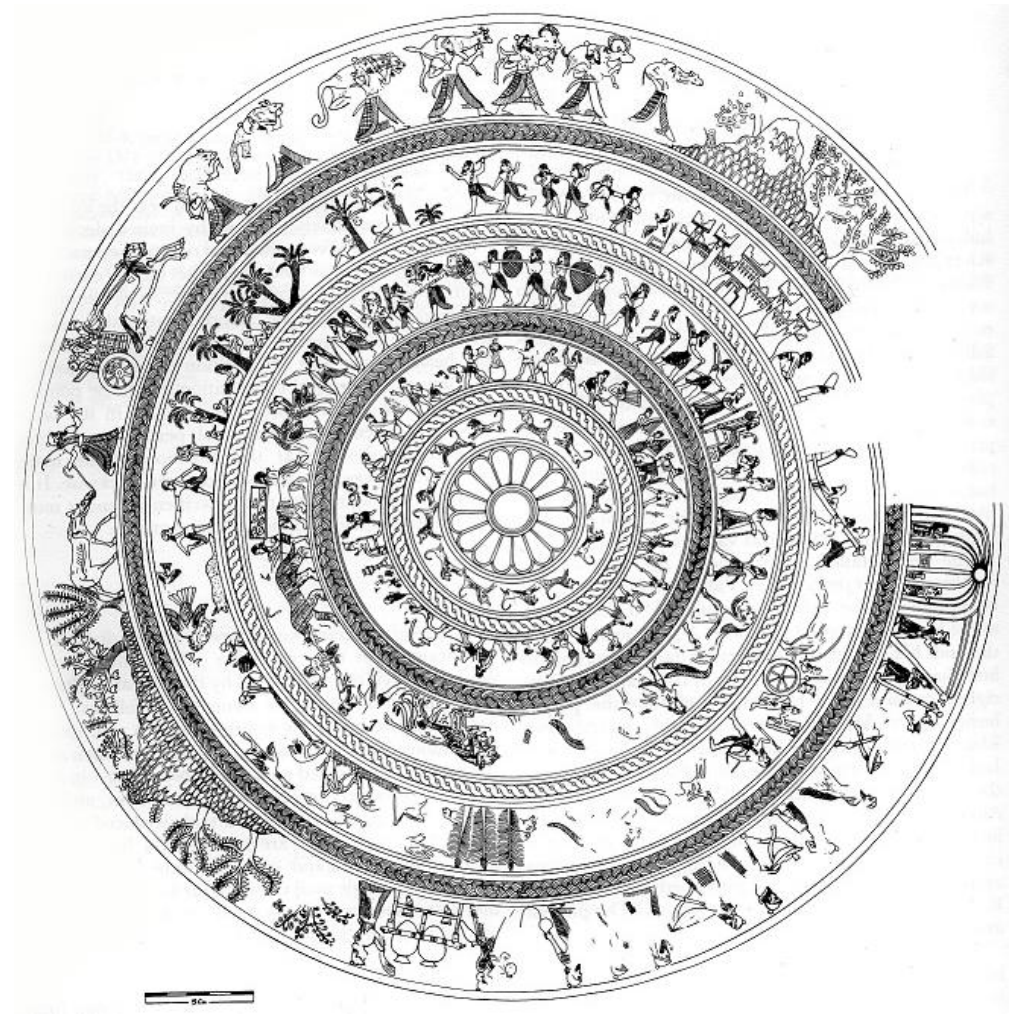

Figure 3. Arjan Cup (Plate) from Ealam Civilization, 800 BC, now at National Museum of Iran

Sporting Art is a unique genre of fine arts. Sporting motifs in art history are relevant for a sport historical approach, given that the painter or artist is presumably attempting to capture and express the spirit of his subject, which he as an artist recognizes and feels subjectively. Sporting art is one form of various visual sources in general and artistic work in order to achieve a better understanding of the past of sports (Krüger, 2018).

Zoorkhaneh is one of the oldest sports in Iran and the traditional gymnasium of urban in the world. In organizational terms, the major and most socio-politically significant locus of athletic activity in pre-modern Iran was the zoorkhaneh, which means 'house of strength' (Amirtash, 2008).

The roots of this sport has been influenced by Mithraism (1000 BC) and three moral components in ancient Iran are 'Good Thought, Good Deed, and Good Word'. This ritual has been practiced from the ancient times in most parts of Iran as well as other countries such as Afghanistan, Tajikistan, Azerbaijan, Iraq, Pakistan, and India. The related terms in pre-Islamic and early Islamic sources show the presence of this sport at that time. Some other evidence is mentioned in Hedāyat al-mota allemin from the 10th AD and the Islamic period (Sedigh Imani, 
2008). However, it seems that most terms which are now common in Pahlevani and Zoorkhanei rituals go back to the thirteenth century AD (Tolou Kian, 2010).

A number of different exercises are performed in a certain order. Formerly these exercises led to the main event, wrestling, but now wrestling is practiced separately. The exercises did not constitute sport in the modern sense, as their aim was physical exercise rather than contest; even in wrestling the contenders would often be separated before a decisive throw so as to spare one of them the humiliation of defeat. Zoorkhaneh structure are made to a fixed pattern. In the middle of main room is a pit where exercises are performed and surrounded by spectator stands. One can enter the main room only through a relatively short door, the goal seems to be to cause everyone who enters to bend, which is a symbol of humility (Chehabi, 1995).

Pahlevani and Zoorkhanei rituals - traditional Iranian sport - were registered as world heritage in 2010 by UNESCO. It concerns a ritual collection of gymnastic and callisthenic movements performed by ten to twenty men who wield instruments symbolizing ancient weapons. The Pahlevani ritual is held in a place named Zoorkhāneh and the callisthenic movements are based on the music and poems of the 'Morshed' (Master) who leads the performance of the Pahlevani ritual (Masaeli, Torabi Farsani, and Mortazavi, 2020).

Figure 4 shows a picture of the Zoorkhaneh Sports Museum in Birjand, Iran.

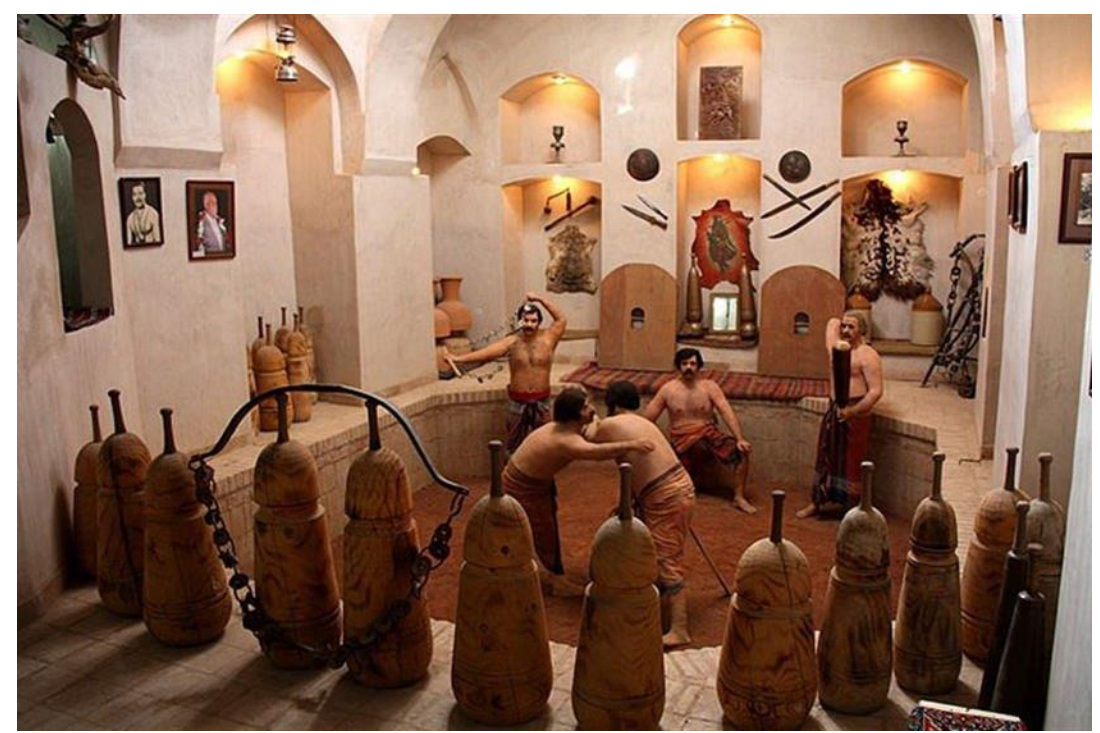

Figure 4. Museum of Zoorkhaneh Sport in Birjand, Iran

Another ancient sport of Iran is polo which is named Chogan in Persian language. This sport added in list of UNESCO as world heritage in 2017 (UNESCO, 2021). This game was formed in Iran around $600 \mathrm{BC}$ and was played during the Achaemenid period. This game was first for preparing soldiers and then entertainment. It has also been considered in the Sassanid period. During the Safavid period, it became a game of interest to the empire. As far as the main square of the capital of that time in Iran, namely 'the Naghshe Jahan', is designed to run this game. 


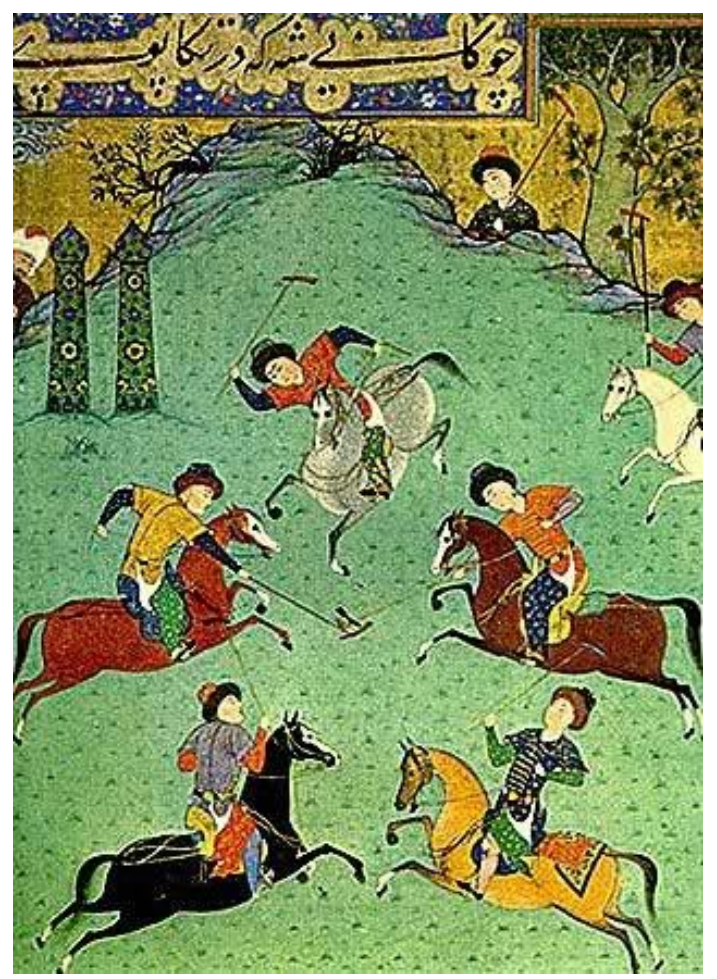

Figure 5. Polo Game (Chogan) - Miniature form Tabriz. Now in Sankt-Petersburg (Russia)

Fair play has been much emphasized in the sport history of Iran. The ideals of Iranian chivalry and sportsmanship are expressed by the notion of pahlavan. A pahlavan is not a mere champion, but also a moral exemplar who is just, fair, self-abnegating and kind to the weak. This culture has its roots in the prehistoric period of Iran and in each of the periods of ancient history, post-Islamic history and contemporary times, mythical figures have been introduced based on it. The historical sports myths of Iran have achieved a lasting name based on this culture. Four mythical characters in Iranian sports society are 'Rostam' who is a legendary personality in the Iranian Book of Kings with the Persian name as 'Shahnameh'; 'Imam Ali' is another legendary person, especially for Shii Muslim; 'Pourya-ye Vali' (1255-1322 AD) was a traditional wrestler and a poet who is considered as a championship by Iranian people after more than 6 centuries due to self-sacrifice in handing over the championship to a needy person and despite his prominent position as a champion, he always tried to help the needy. Contemporary legendary champion is 'Gholamreza Takhti', who has become popular based on ethical and self-sacrifice behavior (Chehabi, 1995).

Before the advent of modern sports in Iran, zoorkhaneh and wrestling and some disciplines such as swimming, shooting, fencing, horse-riding, acrobatic movements and the like were traditionally popular. In addition to these sports, which were held in local ways, some national games such as 'Alak Dolak', 'Cheltub' and similar cases were held in different parts of Iran. 


\section{Modernization Sport in Iran}

At the beginning of the twentieth century, modern sports appeared in Iran. A review of the documents shows that a variety of modern sports were introduced to Iran in the ways described in Table 1.

Table 1. Ways of introducing the Modern Sports to Iran

\begin{tabular}{|c|c|c|}
\hline Row & Ways & Explanation \\
\hline 1 & Embassies & Transferring through facilities created by embassies such as the UK \\
\hline 2 & $\begin{array}{l}\text { Oil Contractor } \\
\text { Companies }\end{array}$ & $\begin{array}{l}\text { Creating recreational and sports facilities for British employees in the oil } \\
\text { companies and familiarizing Iranians with these sports }\end{array}$ \\
\hline 3 & $\begin{array}{l}\text { Religious } \\
\text { missionaries }\end{array}$ & $\begin{array}{l}\text { Establishing religious centers, especially by Christians, and launching some } \\
\text { games such as football and the like }\end{array}$ \\
\hline 4 & Students & $\begin{array}{l}\text { Presence of Iranian students in universities around the world and acquaintance } \\
\text { with different types of sports and bringing them to Iran }\end{array}$ \\
\hline 5 & The royal family & $\begin{array}{l}\text { Sports experience of the royal family and their relatives on foreign trips and their } \\
\text { transfer to the country }\end{array}$ \\
\hline 6 & Military & $\begin{array}{l}\text { Military personnel sent abroad to undergo military courses and get acquainted } \\
\text { with sports and transfer them to Iran }\end{array}$ \\
\hline 7 & Immigrants to Iran & $\begin{array}{l}\text { Introducing and activating sports by immigrants to other countries and trained in } \\
\text { that field }\end{array}$ \\
\hline
\end{tabular}

In general, the emergence of modern sports in Iran was from the late Qajar period. Prince Fereydoun Mirza Malkam, as the first Iranian athlete took part in the 1900 Paris Olympic Games in individual fencing. Considering that the news about his participation in the Olympic was not published in the popular Iranian media of that time; it can be concluded that at that time 'modern sports' was not the focus of Iranian people and government. From 1921 and at the end of the Qajar period and the beginning of the Pahlavi period in Iran, a modern sport was developed. In 1923, 'Mir Mehdi Verandah', who had returned to Iran from Europe after graduating in sports, made a tireless effort to promote European sports in Iran (Ghasemi, et al, 2020).

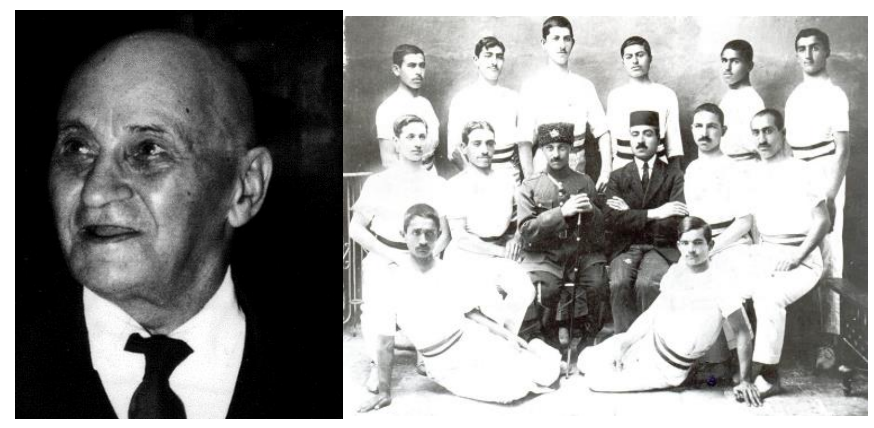

Figure 6. Mir Mehdi Varzandeh, Father of Modern Iran's Sport

During these years, sports clubs were established in Iran, and the structure of management and development of modern sports was first established in education in 1927, and then the Independent Sports Organization in 1934 in the government structure. Subsequently, national sports federations were formed and in 1947, Iran became a member of the International Olympic Committee and participated in the 1948 London Olympic Games and won first medal 
in weightlifting. Over more than seven decades, Iran's sports structures for modern sports management have undergone many changes. At present, structures such as the 'Ministry of Sports and Youth', 'National Olympic Committee', '51 National Sports Federations', 'University Sports Organization', 'School Sports Organization' and other similar cases are managing and administering sports in Iran (Ghasemi, et al., 2020). Wrestling was the most popular sport in Iran until 1970s, as Iranians and foreigners thought, but now it has been replaced by football almost everywhere in the world (Chehabi, 1995).

Sport can be a central part of peoples' culture and can create a tourism image for a destination (Gammon, Gregory, and Emma, 2013). The wrestler Gholamreza Takhti (1930-67) is generally recognized as the greatest Iranian sports legend of the twentieth century. Other Iranian wrestlers have won more medals than Takhti; his enduring fame and popularity is not only due to his athletic strength but also due to his moral role model in the values of traditional Iranian chivalry (Chehabi, 1995).

Mass media has had a significant role on sport development in Iran. The press media had entered Iran since the 18th century, but the period of its growth and development was in the late nineteenth and early twentieth centuries, that is, the period of the emergence of modern sports in Iran (Khaje Sarvy and Nazaryan, 2019). There has been little or no news of sports activities since 1871, but since 1920 the share of sports news in publications has expanded, and in the 1930s some sports magazines were established. This trend continues until it reaches its peak in the first decade of the 21 st century, and with the advent of emerging new media, its influence decreases over time. Radio media came to Iran in the $1925 \mathrm{~s}$, but it took some time to expand. In the first radio programs, Zoorkhaneh sports were broadcast with special music and the voice of a professional Master named 'Shire Khoda'. From the 1960s onwards, with live broadcasts of sports events on the radio, people gathered in public places to listen to the match reports on the radio. After that, Radio became popular in most homes, and more sports enthusiasts were able to follow sports programs. With the expansion of sports and its enthusiasts in 1999, the first all-sports radio network in Iran was established. Television media came to Iran in 1958. This media has been developed in Iran since the 1960s. At the beginning of the TV broadcast period, the audiences were attracted by sports news. Following the live broadcast of sports events was widely welcomed in Iran. The turning point in the quantitative and qualitative development of radio and television sports programs in Iran began with the 1974 Asian Games hosted by Iran. With the expansion of sports and their audiences, the volume of sports programs increased in radio and television in Iran and the first sports television network was established in 2012. The Iranian Association of Sports Journalists and Photographers was founded in 1990 and became a member of International Sports Press Associations (AIPS) (Ghasemi, Tojari, Kohandel, and Khodayari, 2008).

Economic, political, cultural developments, and especially the development of mass media, have increased the focus on modern sports, especially sporting events. After the participation in the Olympic Games of 1948 London and other international events, the approach of building large sports venues was strengthened. Iran then experienced numerous international hosts. The most important hosting of international events was related to the 1974 Asian Games in Tehran. Iran achieved its best result in the Asian Games and became second. After 1979, the change of 
government in Iran and the beginning of the Islamic Republic, sports activities were influenced by religious views. For a while, most of activities has become slow and after some years start to grow. In 1980, the war between Iran and Iraq began, and this long 8-year war until 1988 had major negative effects on various aspects of the country, including sports. Iran did not participate in the 1980 Moscow and 1984 Los Angeles Olympics for political reasons. After the war and with the beginning of the construction period, sport was again considered. The first appearance of the Iran's convoy in the Olympic Games was in 1988 in Seoul, where it earned a silver medal and ranked $36^{\text {th }}$ (Ghasemi, et. al., 2020).

School sports have been considered since the beginning of the modern era, and physical education classes and extracurricular activities have been activated in schools. With the rise of modern sports in Iran, the educational system in schools trained physical educators (Sajjadi, 2013). This marked the beginning of academic activities for the training of physical educators in the 1960s. With the beginning of the physical education field in the Iran's university system, this field was welcomed and within five decades, various specialized fields in sports sciences were formed. Entering the 21st century, various disciplines of sports science in associate, bachelor, master and doctoral degrees were established in Iran's universities. In the way that universities taught interested people in the fields of 'sport physiology', 'sport management', 'motor behavior', 'motor biomechanics', 'sport pathology', 'sport sociology', 'sport psychology', 'sport engineering' and other specialized fields. Today, sports sciences in Iran are among the most popular academic disciplines (Ghasemi, et, al., 2020).

The presence of women in sports has been one of the most important factors in the development of modern sports. In the 1970s, women's sports in Iran grew exponentially. With the beginning of the Islamic Revolution of Iran in 1979, this growth trend decreased for a while, but after the Iran-Iraq war, it grew rapidly. Iran first won a medal in the Asian Games by women, and for the first time in the history of Iran's sports, an Iranian woman named Kimia Alizadeh won a bronze medal in taekwondo at the 2016 Rio Olympic Games. These results are a turning point for women's sports in Iran (Rasekh, Zareian, Ghasemi, and Rezaie, 2019).

\section{Discussion}

A review of the history of sports developments in the prehistoric period of Iran shows that Iran, with the advent of the first civilizations, was one of the main places in introducing sports activities with recreational, religious and defense approaches.

In the period of ancient history and the existence of documents such as 'Hasanlu Golden Cup', 'Arjan Cup' and the writings of historians, show that sport has had a special situation in Iran. For example, the sport of zoorkhaneh with emphasis on religious and defensive customs is rooted in the ancient history of Iran, which has undergone various changes over time and influenced by historical developments, but its basis is still preserved. Ancient sports etiquette is rooted in Iranian culture and emphasizes the need for heroes to have moral qualities and help others. Well-known myths in the ancient history of Iran have been those who have had these outstanding features prominently. Attention to preparation along with competition and fun has been the basis for the creation of games such as polo in ancient history. This approach pays 
attention to the role of games and sports in education and preparation in the ancient history of Iran.

In the modern era, sport was introduced to Iran by embassies, students, the military, immigrants, and other representatives in the late nineteenth and early twentieth centuries and grew rapidly. Sports clubs increased in the cities of Iran and school sports were considered and then sports organizations were formed. Sports events flourished in Iran and with the formation of sports organizations and membership in international organizations, the ground was prepared for participation in international sports events. By winning medals from important international events such as the Olympic Games and the development of media covering the achievements of Iranian athletes, sport has gradually become an important and popular phenomenon. Developing the sport sciences and the universities became the basis for training sports specialists and the growing tendency of those interested in academic disciplines to enter this field. Today, the sports industry in Iran has found a growing trend with the development of clubs, school sports, university sports, workers' sports, and military sports. The presence of women and the increasing attention of Iranian people to modern sports is one of the important and effective reasons for sport development in Iran. To the extent that women's success in sports has provided a great incentive for more people in the community to participate in sports.

\section{Conclusion}

Iranian sport has undergone many changes throughout history. Signs of attention to sports from prehistoric times, ancient history and modern history are quite evident. A review of these developments shows that the position of sports in Iran, in addition to cultural and value aspects with an industrial approach, has taken a growing trend. The role of women in Iran's sports is growing and it seems that the growth of women's sports in the future will significantly strengthen the position of Iran's sports in the world. Also, the prosperity of sports sciences in Iran will provide new opportunities to identify the least dangerous ways of sports development. 


\section{References}

Amirtash, A. M., (2008). Zoorkhaneh and Varzesheh-e- Bastani. Journal of Movement Science \& Sports 5, no. 1 (2008):

https://www.sid.ir/en/journal/ViewPaper.aspx?id=107016.

Chehabi, H. E. (1995). Sport and politics in Iran: the legend of Gholamreza Takhti.

The International Journal of the History of Sport 12, no. 3: 48-60.

Gammon, S., Gregory R., and Emma W. (2013). Examining the Olympics: Heritage, identity and performance. Taylor \& Francis 19, no. 2 : 119-124.

Ghasemi, H., and Keshkar, S. (2011). Cultural and social foundations of physical education. Tehran: Bamdade Ketab.

Ghasemi, H., Tojari, F., Kohandel, M., and Khodayari, A., (2008). Media Activity on Sport. Tehran: Bamdad Book.

Ghasemi, H., Keshkar, S., Rasekh, N. and Izadparast, L. (2020). Fudamentals of Sports Sciences. Vol. 1. Tehran: Andisheara.

Grégory Q. (2017) Writing Swiss Sport History: A Quest for Original Archives, The International Journal of the History of Sport, 34:5-6, 432-436, DOI:

$10.1080 / 09523367.2017 .1378183$

Khaje Sarvy, G. R., and Nazaryan, S.M. (2019). Press In Iran from the Beginning until the advent of the first Pahlavi: from A monarchy (courtier) form to Double Consciousness. Political Sociology of Iran 1, no.4 (2019):73-104.

Krüger, M. (2018) German Sport History as Reflected in 'Sporting Art', The International Journal of the History of Sport, 35:17-18, 1748-1776, DOI: $10.1080 / 09523367.2019 .1586671$

Masaeli, M., Torabi Farsani, N., and Mortazavi, M. (2020). A study on tourist demand for Pahlevani and Zoorkhanei rituals as ancient Iranian sport. Journal of Sport \& Tourism 24, no.1:19-29.

Rasekh, N., Zareian, H., Ghasemi, H., and Rezaie Z. (2019). Championship Sports for Iranian Women: Challenges, Opportunities and Solutions. New Approaches in Sport Sciences 1, no. 1: 99-116.

Sajjadi, N. (2013). History of physical education and sports in Iran. Tehran: Sport Sciences Research Inistitut of Iran.

Salahshoor A. (2018). The survey of Visual and Aesthetical Elements of Motifs on the Potteries of Iran's prehistory (with Emphasis on the Chalcolithic Period). ph. 7 (14): 109-120, http://ph.aui.ac.ir/article-1-483-en.html

Sedigh Imani, M. (2008). Code of chivalry and ancient sports in the history. Ketab Mah Honar 121 :42-57.

Tolou Kian, F. (2010). Zoorkhaneh sport education (history, culture, traditions, places, tools, operations, and physical benefits of heroic sports). Tehran: Safir Ardehal.

UNESCO (2021). Chogān, a horse-riding game accompanied by music and storytelling. 